\title{
Experiences of Registered Nurses in the Care of COVID-19 Patients: A Phenomenological Study
}

\author{
Sunil Salina ${ }^{1} \quad$ K.C. Leena ${ }^{2}$ \\ 1 Department of Community Health, Nursing, College of Nursing, \\ Nettur (PO), Thalassery, Kannur, Kerala, India \\ 2 Yenepoya Nursing College, Yenepoya Deemed to be University, \\ Derlekatte, Mangalore, Karnataka, India \\ J Health Allied Sci ${ }^{\mathrm{NU}}$ 2022;12:139-144.
}

\author{
Address for correspondence Sunil Salina, MSc (N), Department of \\ Community Health, Nursing, College of Nursing, Nettur (PO), \\ Thalassery, Kannur, Kerala 670105, India \\ (e-mail: salina.surabhi@gmail.com).
}

\begin{abstract}
Keywords

- COVID-19 and nursing

- COVID-19 nursing challenges

- Lived experiences caring COVID-19 positive

- COVID-19 warriors

Introduction Coronavirus disease 2019 (COVID-19) is the infectious disease caused by the most recently discovered coronavirus. This new virus and disease were unknown before the outbreak began in Wuhan, China, in December 2019. COVID-19 is now a pandemic affecting many countries globally. The aim of this study was to examine the lived experiences of staff nurses who are involved in care of COVID-19 patients during COVID-19 outbreak in Kerala.

Methods Qualitative phenomenological approach was used in this study. Data was gathered from six registered nurses through telephonic interview and video call. Moustakas's structured method of inductive data analysis was used in the study.

Results Three themes were evolved from the current study. They are challenging profession, balancing profession with family, and from uncertainty to satisfaction.

Discussion Findings drew from the current study highlight ever seen areas in health industry. The health workers are the major workforce in any epidemic outbreak. Concern to their health needs to be one of the higher priorities. It is ideal to talk about infection control and use of personal protective equipment. But the practical implication needs to be further explored in connection with infection control.
\end{abstract}

\section{Introduction}

Winston Churchill, when he was 15 years old, wrote regarding influenza pandemic in 1890, "Oh, how shall I its deeds recount- Or measure the untold amount - Of ills that it has done?" He wrote this to explain the devastations and uncountable and unpredictable losses of the pandemic.

Pneumonia of unknown cause was first reported to the World Health Organization (WHO) country office in China on December 31, 2019. It was occurred at Wuhan, China. The outbreak was declared a Public Health Emergency of International concern on January 30, 2020. On February 11, 2020,
WHO announced a name for the new coronavirus disease: coronavirus disease 2019 (COVID-19). As of June 11, 2021, there are 17,45,02686 confirmed cases of COVID-19 reported in the world. Due to COVID-19, 37,70,361 confirmed death occurred by June 2021. According to WHO, 215 countries, areas, or territories are affected with COVID-19 (WHO 2021). India has 2,92,74,823 confirmed cases of COVID-19 case and 3,63,079 deaths due to COVID-19 as on June 11, 2021 as reported by WHO. ${ }^{1}$

This disease being novel is a situation that the health-care industry was unprepared for. This is certainly due to the questions surrounding its transmission and sequelae. No
DOI https://doi.org/ $10.1055 / \mathrm{s}-0041-1736276$. ISSN 2582-4287.

\footnotetext{
(c) 2021. Nitte (Deemed to be University). All rights reserved. This is an open access article published by Thieme under the terms of the Creative Commons Attribution-NonDerivative-NonCommercial-License, permitting copying and reproduction so long as the original work is given appropriate credit. Contents may not be used for commercial purposes, or adapted, remixed, transformed or built upon. (https://creativecommons.org/ licenses/by-nc-nd/4.0/) Thieme Medical and Scientific Publishers Pvt. Ltd., A-12, 2nd Floor, Sector 2, Noida-201301 UP, India
} 
doubt even the most developed countries and their healthcare sector are overwhelmed with this never faced threat to humanity. The most difficult challenge is to master the know-how of handling the clients while protecting self, colleagues, and own families. Shortage of personal protective equipment (PPE) and lack of prophylactic measures is a huge challenge, in addition to the negativities surrounding diagnosis of COVID-19 and quarantine measures. Loss of lives of health-care providers in large numbers has led to increased threat perception among direct care providers.

In an overpopulated developing country like India, where health is a fundamental right and state has an obligation to provide primary health care, the first confirmed case reported on January 30, 2020 at Thrissur in Kerala. Kerala became the first state to handle earliest case of COVID-19 in India. Kerala has the lowest mortality rate of $0.6 \%$ among all states in India. Kerala's success in containing COVID-19 has been widely praised. ${ }^{2}$

Boris Johnson, Prime Minister of United Kingdom on his discharge from hospital after treatment for COVID-19, gave a speech where he expressed his gratitude to nurses. He used the word "astonishing" to describe the care he received from the nurses. He added that he would be grateful to nurses to the rest of his life.

According to a study published by NIHR, the nurses experienced certain areas where "missed care" occurred. They identified certain barriers for this missed care, like difficulties in communication and interpersonal relationship caused by PPE. The nurses expressed difficulties in organizing hospital equipment in secure environment, lack of time, and problem in integrating knowledge and skill while caring for patients during pandemic. ${ }^{3}$

The results from mixed method study to identify the experiences of nurses during COVID-19 pandemic showed certain themes related to resilience. The study found medium resilience in areas where an imbalance occurred between certainty and uncertainty. The study reported that nurses are at midway from ability to grow and difficulty in copying. However, most of the nurses reported high resilience related to the theme "proud to be a nurse." 4

Nurses and the other health workers are at the forefront of COVID-19 response, providing high-quality, respectful treatment, and care, leading community dialogue to address fears and questions, and in some instances, collecting data for clinical studies. Quite simply, without nurses, there would be no response. ${ }^{5}$

\section{Aim}

The aim of the study was to explore the experiences of registered nurses while caring for patients with COVID-19.

\section{Methods}

\section{Overview and Design}

A qualitative transcendental phenomenological approach was used in this study. A phenomenology is an approach in qualitative research that describes the lived experiences of different individuals. The transcendental phenomenology depends on different lived experiences of participants, thereby generating essence of those experiences. ${ }^{6}$ The foundation for this study is post-positivism paradigm in which multiple perspectives from different participants are collected and rigorous data analysis technique was utilized.

\section{Sampling and Participants}

Purposive sampling using snow ball technique was utilized for the study. This method of sampling helps to identify participants who have similar experiences and have undergone similar professional experiences. Six staff nurses were selected from one district that were in COVID-19 treatment team. This way homogeneity could be maintained. All the staff nurses were selected after having 14 days of duty in COVID-19 treatment centers. The participants were staying in different isolation centers. Participants were contacted over telephone and one to one, face to face interaction was done using ZOOM platform.

\section{Sample Characteristics}

All staff nurses were working in government sector. They had professional experience ranging from 10 to 16 years and their mean age was 41 years. All were married and had spouse and children. All were residing in specified COVID-19 treatment centers and all participants were on quarantine period after 14 days of duty at COVID-19 treatment centers. The participants were staying in different isolation centers of the district. So, the settings of the study are different isolation centers designated for the health professionals to be in isolation period after their 14 days duty in COVID-19 treatment centers. All participants belonged to govt sector, but were working in COVID-19 teams of different hospitals.

\section{Data Collection}

"Researchers in the phenomenological mode attempts to understand the meaning of events and interactions of ordinary people in particular situation."7

Data collection was done with semistructured interview using the following topics.

- What were your experiences in caring for dreaded disease COVID-19?

- What were your worries?

- What were your experiences of being inside of PPE for a prolonged time period?

- What were the attitudes/behavior of patients with COVID-19 toward the care they received, health team members and diagnosis of COVID-19?

The participants were first contacted over telephone and gave a brief overview of the study and their willingness to participate in study was obtained using a consent form. Then each participant was contacted through ZOOM platform and semistructured interview was carried out using the abovementioned questions for 30 minutes. The meeting was recorded and was heard repeatedly to note down the conversation. Verbatim was transcribed with process recording. 


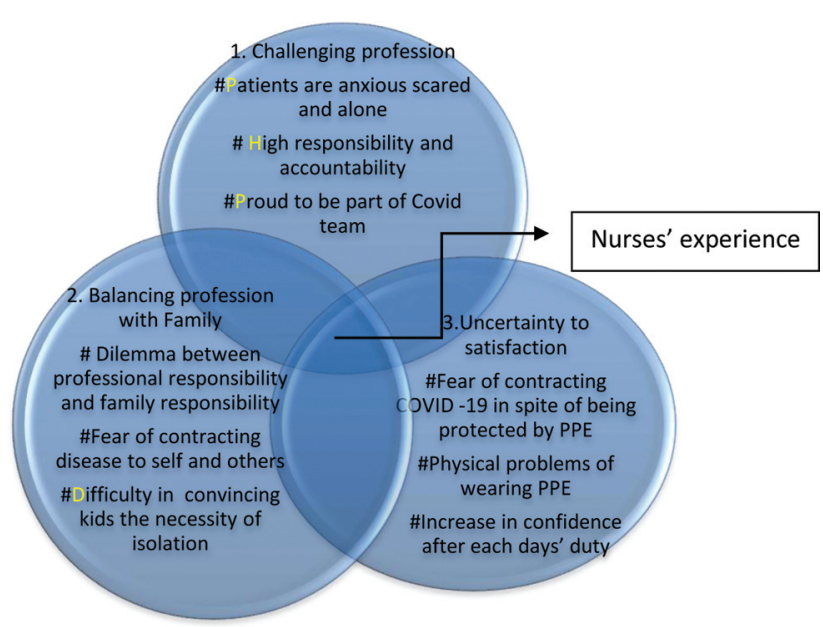

Fig. 1 Interrelationship themes and key concepts in nurses' experiences. COVID-19, coronavirus disease 2019; PPE, personal protective equipment.

They were given an opportunity to write down their views. It was sent back to the researcher after taking a scanned copy. The initial draft of experiences was prepared and was sent to each participant separately keeping the confidentiality. Data collection was completed with three rounds namely, initial contact over Zoom (average of 30 minutes), reviewing the written views of participants and review of final draft by participants. Hence, an average of 50 minutes of data collection period was taken for one participant.

Rigor is simply defined as the quality or state of being very exact, careful, or with strict precision or the quality of being thorough and accurate. Debriefing with the participants was done multiple times. Cross checking of the data was done to achieve triangulation. Member check was done to ensure credibility. ${ }^{8}$

Data collection was completed within 12 days and ended up in saturation of data, when no further theme or new information emerged to add to the understanding of the phenomenon. Experiences are integrated in - Fig. 1.

\section{Data Analysis}

In this study, Moustakas's structured method of inductive data analysis was used. ${ }^{9}$ The transcript from each participant was recorded by the researcher and the participants were asked to write down their views. The researcher had read the transcript thrice to immerse in the data. After reading, memos were noted down and further immersion was made and finally key concepts could be highlighted. After initial immersion, the following steps were followed:

- Equal value and importance were given to each statement and coded with description-horizontalization.

- Invariant constituents of experience were determined by reduction and elimination of statements that were not horizon of the experience.

- Similar constituents were grouped in one cluster. Each cluster was given a thematic label. Initially several themes have evolved and finally three core themes of experience were reduced.
- These themes were utilized to construct textural, structural, and textural-structural components and finally overall essence of experience was culminated.

\section{Credibility and Dependability}

Participants view for credibility is the only justifiable evaluation of the results. Member check is the most critical credibility technique. ${ }^{10}$ In member check, each participant was given an exclusive access to their interview transcript and invited to read them thoroughly for clarity and accuracy and to provide additional insight and information.

\section{Limitations}

- Since most of staff nurses know each other personally and professionally, the researcher tried to protect their anonymity, but could not be guaranteed.

- The researcher had to wait for the staff nurses who were on COVID-19 duties, for their work quarantine period. It was known that the staff nurses had tiresome duty and they were caring for the patients with same diagnosis. A similarity in data was expected. The researcher did everything to eliminate biases and set them aside.

\section{Results}

Three themes were emerged from the experiences of staff nurses:

- Challenging profession.

- Balancing profession with family.

- From uncertainty to satisfaction.

It is presented in - Table 1. The quotes presented in the results section use pseudonyms to protect the identity of participants.

\section{Challenging profession}

Majority (50\%) of participants reported nursing as a challenging profession. They had been continuing the professional life as a means to bread. But this present opportunity gave them added responsibility and they portrayed themselves as heroes. They could identify that they are sole source of support and scope for the patients who were tested positive for COVID-19. They were proud to be a part of COVID-19 warrior team of the state.

2. Balancing profession with family

Nurses always face the problem or difficulty to maintain a balance with family and professional life. When it comes to pandemic period, there happened the issues like being in isolation or quarantine for specific period. In the present study, $66.66 \%$ of the participants expressed similar concerns. As the study conducted during the first wave of COVID-19, the quarantine rules were more rigid. So, all the nurses who were involved in the current study were in institutional quarantine period after their prescribed duty period in COVID-19 treatment centers. Most (50\%) expressed their worries of being away from their kids, 
Table 1 Themes and key concepts (with supporting quotes) of experiences as expressed by staff nurses

\begin{tabular}{|c|c|c|}
\hline Themes & Key concepts & Supporting quotes \\
\hline $\begin{array}{l}\text { 1. Challenging } \\
\text { profession }\end{array}$ & $\begin{array}{l}\text { 1.1 Great challenging to care for patients } \\
\text { who are extremely anxious, alone and } \\
\text { scared } \\
\text { 1.2 High responsibility and accountability } \\
\text { for being the only scope of confidence } \\
\text { for COVID-19 patients } \\
\text { 1.3 Proud to be a part of COVID-19 } \\
\text { treatment team of the state }\end{array}$ & $\begin{array}{l}\text { (Zara) "All patients are anxious and they are tensed of dying. } \\
\text { They are seeing the news and stories from America, Britain.... } \\
\text { We are only people that they can see. So even in PPE, they are } \\
\text { confident with us" } \\
\text { (Sati) "Patients were stressed. Sometimes they are disturbed } \\
\text { too and show anger towards us. Some of the patients } \\
\text { complained about the food they received. But it was not a major } \\
\text { problem." } \\
\text { (Susan) "Some patients were demanding. I was proud to be a } \\
\text { part of this team. I have asked for this duty. Govt is providing all } \\
\text { the protective equipments for us." }\end{array}$ \\
\hline $\begin{array}{l}\text { 2. Balancing } \\
\text { profession with } \\
\text { family }\end{array}$ & $\begin{array}{l}\text { 2.1 Perceived dilemma between } \\
\text { professional responsibility and family } \\
\text { responsibility } \\
\text { 2.2 Fear of contracting disease to self and } \\
\text { others } \\
\text { 2.3 Difficulty in making small kids to } \\
\text { understand the necessity of isolation }\end{array}$ & $\begin{array}{l}\text { (Minnu) "I was sad for being apart from the family especially } \\
\text { from the younger kid. But my husband was very supportive. My } \\
\text { kid was not able to grasp the idea of being away from mom." } \\
\text { (Zara) "family support was high and they are proud for this } \\
\text { venture. Though I wore PPE, I doubt that I may get the disease. If } \\
\text { so, I will infect others too. The } 14 \text { days quarantine is helpful" } \\
\text { (vani) "initially I felt fear of contracting the disease. I just } \\
\text { imagined the virus is infecting me. Even inside the PPE also, I was } \\
\text { doubtful initially. My husband told not to make video call. Since } \\
\text { my kids are seeing me through video, they are asking me to } \\
\text { come back." } \\
\text { (kiran) "I was willing for the duty, but my family was doubtful. } \\
\text { Since my husband was also on COVID duty, I had to keep the } \\
\text { children with one of my relatives. My kids kept on asking the } \\
\text { reason for not coming back to home after duty. } 14 \text { days } \\
\text { quarantine was helpful. Even if I am be infected, I can stay myself } \\
\text { away from infecting others." }\end{array}$ \\
\hline $\begin{array}{l}\text { 3. Uncertainty to } \\
\text { satisfaction }\end{array}$ & $\begin{array}{l}\text { 3.1 Fear of caring patients with COVID-19 in } \\
\text { spite of being protected by PPE } \\
\text { 3.2 Physical problems of wearing PPE } \\
\text { 3.3 Increase in confidence after each days' } \\
\text { duty }\end{array}$ & $\begin{array}{l}\text { (Vani) "initially I felt fear of contracting the disease. I just } \\
\text { imagined the virus is infecting me. Even inside the PPE also, I was } \\
\text { doubtful initially. But as days are getting over, I was getting } \\
\text { confidence. When the patients' swab result gets negative, I felt } \\
\text { much satisfaction and I thanked God." } \\
\text { (Zara) "I joined this venture with much professionalism. When I } \\
\text { wore PPE, } 10 \text { minutes after that, I started sweating. Actually I } \\
\text { wanted drink water. But I could not remove PPE. When we give } \\
\text { water to patients, I longed for it. It was like burning sensation." I } \\
\text { was so distressed on first day. Then I realized the fact. We had } \\
\text { waited for nearly } 4 \text { h to have a sip of water. But later it became a } \\
\text { routine. I started to adjust with it. As the patients are getting } \\
\text { better, I felt so happy. Though we have suffered a lot, we could } \\
\text { see the fruitful result of it." } \\
\text { (Sati) "when I wore PPE, I understood that even a bit of air is not } \\
\text { entering inside the PPE. I was sweating like anything. I could not } \\
\text { see others, due to perspiration; sometimes the goggle will come } \\
\text { down, but could not adjust it. Even I could not sit properly. Night } \\
\text { duty was horrible. Doffing (Taking Off) of PPE was another } \\
\text { problem. It has adhered to body with sweat. But what was the } \\
\text { best thing out of it is, patients were getting good, with no } \\
\text { complications." } \\
\text { (susan) "since some patients were demanding, I was little bit } \\
\text { disappointed initially. They wanted non veg foods, and some } \\
\text { other items. Govt was providing everything for free of cost. That } \\
\text { made them demanding, I felt so. But later I could make up mind, } \\
\text { by understanding the feelings of patients. But as days } \\
\text { progressed, I could deal with these types of issues easily. We } \\
\text { need to wear PPE only for } 4 \text { h; even then it was one of most } \\
\text { challenging situation for me." } \\
\text { (Kiran) "I could manage the stress of CovID -19 healthily. But } \\
\text { what was disturbing was the attitude of the patients and } \\
\text { experience of being inside the PPE. But the no of patients } \\
\text { getting negative results after swab test was very encouraging. I } \\
\text { realized that the fruit of hard work is always sweet." }\end{array}$ \\
\hline
\end{tabular}

Abbreviations: COVID-19, coronavirus disease 2019; PPE, personal protective equipment. 
who were not in a position to understand the concept of quarantine period.

3. Uncertainty to satisfaction

Most (83.33\%) of the nurses had gone through this situation. In spite of being protected by PPE, fear of being contracted by virus was their major concern. But as days were passed, uncertainty had turned out to be care satisfaction. The responses from the patients initially were very disappointing, but later the patients started believing and showed gratitude toward nurses and other health-care professionals. These in turn helped nurses to gain confidence and satisfaction.

\section{Discussion}

The present study revealed certain areas that have not been explored so far. The world has been facing different type of pandemic in the recent years, namely Ebola, H1N1, Nipah, and now COVID-19. The outmost aim in different outbreak has been the safety of mankind. These epidemics have taught us the need to be prepared anytime. The health-care warriors have to be treated with outmost dignity, respect, and their life also to be given due significance. The COVID-19 has taken the life of numerous health-care workers, including doctors, nurses, and other health-care workers.

Infection control is a topic that has been discussed most. But most of the time health-care workers are taking the infection control activities as granted. The need for proper hand washing and use of mask and other PPE should be a routine practice. A new health culture has to be emerged stressing hand washing, and use of standard precaution while taking care of patients in any health-care setting.

Doctors, nurses, and other health workers should be given first priority in public policy. They spare their family and other personal affairs during these epidemics. Health has to be given highest priority while planning for country's policy development.

World scientists on COVID-19 met at the WHO Geneva headquarters on February 11 to 12,2020 to assess the current levels of knowledge about the new virus, agree on critical research questions that need to be answered urgently, and to find ways to work together to accelerate and fund priority research to curtail this outbreak and prepare for those in the future. The discussion led to an agreement on two main goals. The first was to accelerate innovative research and second was to support research priorities. ${ }^{5}$

Only fewer studies concerning nurse's experience in pandemic had been done so far. A systematic review was done on nurses' experience of working in acute care settings during a respiratory pandemic. Though nurses have obligation to humanity, they have concern related to work and personal life, reported in systematic review. Nurses have the fear of being infected in pandemic and concerns related to family members. The nurses are facing issues related to scarcity of resources like PPE. The review highlights the stress associated with family separation, heavy workload, and shortage of staff. ${ }^{11}$

Results from a phenomenological inquiry done to understand the experiences of nurses in Turkey who are working with COVID-19 patients showed that nurses need psychological support and cooperation from the society and other health team members. Dilemma and conflicts in related professional role were among the five themes evolved from the study. Increasing professional solidarity was recorded as one subtheme. The study emphasized the need to make nurses feel that they are valuable, safety of the nurses, and proper rewarding of the nurses. ${ }^{12}$

A study was published in Lancet Global Health related to the experience of health care providers during the COVID-19 crises in China. The study was done among nurses and physicians. The study concluded that health-care workers are drained physically and emotionally. Safe guarding of the health-care workers should be given priority. Preparedness in crisis events has to done with proper training. ${ }^{13}$

The present study revealed many themes and subconcepts. Uncertainty to satisfaction was a theme emerged from the current study. A phenomenological enquiry done by Muz and Yüce also concluded a similar subtheme. They identified increasing professional satisfaction as a subtheme. The participants discussed about increased professional satisfaction. They considered themselves as an important member of health-care team. ${ }^{12}$

Another subtheme emerged from the present study was physical problems of wearing PPE. A similar subtheme was emerged from a study done by Robinson and Stinson. The study showed the subtheme as PPE. In that study, nurses discussed the physical issues associated with PPE. ${ }^{14}$

Challenging profession was another theme evolved from the current study. One of the subconcepts was proud to be part of COVID-19 team. A study was done by LoGiudice and Bartos on experiences of nurses during the COVID-19 pandemic. It was a mixed method study. Proud to be nurse was emerged as theme 5 in the study. The nurses shared their views of feeling proud to be nurse on the frontlines during pandemic. ${ }^{15}$

\section{Conclusion}

COVID-19 has undoubtedly caused the greatest challenge of our times to humankind. The health-care industry is quite unprepared and is overwhelmed. Nurses are one of the most decisive workforces involved in care of patients with COVID-19. It is essential to know the context of caring COVID-19 patients in its wholeness in the perspective of the care takers. Such information will help all the stakeholders to devise strategies to handle the challenges. Throwing light on the life of COVID-19 warriors helps the society treat them with dignity, all of which lead to empathetically handling the care of most distressed clients.

Conflict of Interest

None declared.

\section{Acknowledgment}

The investigators are highly indebted to all the registered nurses who took part in this study. In spite of being tired and stressed after the duty hours, they spent their valuable time for the research project. 


\section{Experiences of Registered Nurses in the Care of COVID-19 Patients Salina, Leena}

\section{References}

1 Coronavirus Disease (COVID-19) Pandemic. Accessed Aug 5, 2021 from who.int/emergencies/diseases/novel-coronavirus-2019

2 COVID-19 Kerala. Accessed Aug 5, 2021 from dhs.kerala.gov. in/public-health-2019-n-corona-virus/

3 David R. Learning from the experience of nurses to deliver the best care for covid patients. NIHR 2021. Accessed Aug 5, 2021 from https://www.nihr.ac.uk/blog/learning-from-the-experience-ofnurses-to-deliver-the-best-care-for-covid-patients/27208

4 LoGiudice JA, Bartos S. Experience of nurses during the Covid-19 pandemic: a mixed method study. AACN Adv Crit Care 2021;32(01): 14-26

5 Corona Virus WHO. (COVID -19) Dashboard. Accessed Aug 5, 2021 from covid19.who.int

6 Creswell JW. Qualitative Inquiry and Research Design: Choosing among Five Approaches. Thousand Oaks CA: Sage Publications; 2013

7 Bogdan RC, Biklen SK. Qualitative Research of Education: An Introduction to Theories and Methods. 4th edition Boston: Allyn\& Bacon; 1998

8 Cypress BS. Rigor or reliability and validity in qualitative research: perspectives, strategies, reconceptualization, and recommendations. Dimens Crit Care Nurs 7/8 2017;36(04): 253-263

9 Husserl E. Ideas: General Introduction to Phenomenology. New York: Routledge; 2012

10 Philips DC, Burbuleas NC. Post Positivism and Educational Research. Lanham MD: Rowman \&Little field Publishers; 2000

11 Fernandez R, Lord H, Halcomb E, et al. Implications for COVID-19: a systematic review of nurses' experiences of working in acute care hospital settings during a respiratory pandemic. Int J Nurs Stud 2020;111:103637

12 Muz G, Erdoğan Yüce G. Experiences of nurses caring for patients with COVID-19 in Turkey: a phenomenological enquiry. J Nurs Manag 2021

13 Liu Q Luo D, Haase JE, et al. The experiences of health-care providers during the COVID-19 crisis in China: a qualitative study. Lancet Glob Health 2020;8(06):e790-e798

14 Robinson R, Stinson CK. The lived experiences of nurses working during the COVID-19 pandemic. Dimens Crit Care Nurs 2021;40 (03):156-163

15 LoGiudice JA, Bartos S. Experiences of nurses during the COVID-19 pandemic: a mixed-methods study. AACN Adv Crit Care 2021;32 (01):14-26 